Retrospective Study

\title{
Combined Ablation and Radiation Therapy of Spinal Metastases: A Novel Multimodality Treatment Approach
}

Taylor J. Greenwood, MD1, Adam Wallace, MD1, Michael V. Friedman, MD1, Travis J. Hillen, MD', Clifford G. Robinson, MD $^{2}$, and Jack W. Jennings, MD, PhD ${ }^{1}$

From: ${ }^{1}$ Mallinckrodt Institute of Radiology, Washington University in St. Louis, St.

Louis, MO; ${ }^{2}$ Department of Radiation Oncology, Washington University, St. Louis, MO.

Address Correspondence: Taylor J. Greenwood, MD Mallinckrodt Institute of Radiology

Washington University in Saint Louis 510 S. Kingshighway Blvd. St. Louis, MO 63110 E-mail:

greenwoodt@mir.wustl.edu

Disclaimer: There was no external funding in the preparation of this manuscript. Conflict of interest: Dr. Jennings is on a speaker panel and a consultant for DFINE, INC.

Dr. Hillen is a lab instructor with DFINE, INC. Each author certifies that he or she, or a member of his or her immediate

family, has no commercial association (i.e., consultancies, stock ownership, equity interest, patent/licensing arrangements, etc.) that might pose a conflict of interest in connection with the submitted manuscript.

Manuscript received: 01-29-205 Revised manuscript received: o6-09-2015

Accepted for publication: o6-17-2015

Free full manuscript: www.painphysicianjournal.com
Background: Radiation therapy (RT) is the current gold standard for palliation of painful vertebral metastases. However, other percutaneous modalities such as radiofrequency ablation (RFA), cryoablation, and vertebral augmentation have also been shown to be effective in alleviating symptoms. Combined RT and ablation may be more effective than either therapy alone in palliating painful metastatic disease to the spine.

Objective: To evaluate the safety and efficacy of combined ablation, either RFA or cryoablation, and RT in the treatment of spinal metastases.

Study Design: Retrospective study.

Setting: This is a retrospective study at a single institution.

Methods: Medical records of all patients who underwent ablation of spine lesions at a single institution between March 2012 and June 2014 were reviewed; patients treated with both RT and either RFA or cryoablation concurrently were identified. Pain scores before and after RFA were measured with the numerical rating scale (NRS) ( 0 - 10 point scale) and compared. Procedural complications, changes in general activity level, and pain medication usage after ablation were also recorded. When available, follow-up imaging was evaluated for evidence of residual or recurrent disease.

Results: Twenty-one patients with 36 spine metastases were treated with RT and percutaneous ablation concurrently; either RFA (21/22) or cryoablation (1/22). One patient received 2 separate RFA treatments. Overall, mean worst pain score $(8.0, S D=2.3)$ significantly decreased at both one week $(4.3, \mathrm{SD}=3.1 ; P<.02)$ and 4 weeks $(2.9, \mathrm{SD}=3.3 ; P<.0003)$. Temporary postprocedural radicular pain occurred after one RFA treatment $(4.5 \% ; 1 / 22)$. Seven patients had radiation resistant tumors (renal cell, melanoma, or sarcoma). Post-procedural imaging (median 6 months; range $2-27$ months) showed stable treated disease in 12/13 treatments at 3 months and $10 / 10$ at 6 months.

Limitations: The therapeutic effect of vertebral augmentation versus percutaneous ablation cannot be separated in this retrospective study. Radiation treatment protocols were variable and included both stereotactic body and conventional RT which may have different safety and efficacy profiles.

Conclusion: Percutaneous ablation and concurrent RT is safe and effective in palliating painful spinal metastases and can be effective in those who have radiation resistant tumor histology.

Key words: Interventional spine oncology, pain, percuataneous ablation, radiofrequency ablation, cryoablation, radiation therapy, spine metastases, vertebroplasty

Pain Physician 2015; 18:573-581 
T he most common site of osseous metastases is the spine, which accounts for $40 \%$ of all osseous metastatic disease. Pain associated with these metastases has a significant impact on patients' quality of life (1-6). Treatment of spinal metastases is usually palliative with goals of therapy including timely control of pain, local tumor control to prevent neurological deficits, and mechanical stabilization to preserve function (1). Therefore, historic treatment has been mostly noninvasive, utilizing analgesics, chemotherapy, and radiotherapy. Surgery is traditionally only considered for oligometastatic or radiation resistant tumors (e.g., sarcoma, melanoma, and renal cell), spinal instability, symptomatic neural compression, or intractable pain unresponsive to non-operative measures (1).

For patients with localized pain due to spinal metastases that is uncontrolled with analgesics, systemic chemotherapy, and/or bone-seeking radionuclides, conventional external beam radiation therapy (cEBRT) is the standard of care (7). However, radiation therapy (RT) has several important clinical limitations that emphasize the need for adjunctive or alternative therapeutic modalities. First, many patients' response to RT is unsatisfactory with partial and complete palliation rates of $48-50 \%$ and $15-18 \%$, respectively (8-10). Second, patients often develop recurrent pain, and retreatment with RT is only effective for $40 \%$ of these patients $(9,10)$. Third, patients may not experience pain relief for several weeks $(9,10)$. Finally, once normal tissue dose limits have been reached, recurrent pain at a previously irradiated site or adjacent vertebral level often cannot be re-treated with additional RT.

Recent studies have demonstrated image-guided minimally invasive techniques of radiofrequency ablation (RFA), cryoablation, and vertebral augmentation to be safe and effective in treating symptomatic metastatic osseous disease (11-15). Percutaneous ablation with cement stabilization not only rapidly relieves pain (often immediately post procedure) but it does not require interruption of other systemic therapies (12-14). Some authors have postulated that combined RT and RFA may function synergistically to achieve better outcomes compared with RT or RFA alone (15). This study evaluates the safety and efficacy of combined percutaneous ablation and RT in the treatment of spinal metastases at a single institution.

\section{Methods}

This retrospective study was approved by our institutional review board and was Health Insurance
Portability and Accountability Act compliant. Consent was waived for retrospective study participation. Medical records of all patients who underwent percutaneous ablation of bone lesions at our institution between March 2012 and June 2014 were reviewed. Patients with spinal metastases treated concurrently with either RFA or cryoablation and conventional or stereotactic body radiation therapy (SBRT) were identified. Concurrent treatment was defined as less than 4 weeks between RT and ablation. Prior to undergoing percutaneous ablation, patients were discussed in a multidisciplinary spinal tumor board conference including radiation oncology, radiology, orthopedic spine surgery, and neurosurgery.

On the day of the ablation procedure, pre-procedural worst pain in 24 hours was measured with the numerical rating scale (NRS) (0 - 10 point scale). Analgesic use histories were also recorded by the nurse coordinator. Subsequent pain scores and changes in general activity and analgesic medication use were then obtained via telephone interview one week and one month after the procedure by the nurse coordinator. Analgesic medication use was defined as more, same, or less absolute mg/day. General activity was categorized as more, same, or less compared to pre-procedural levels. When multiple contiguous spinal levels were treated in a single ablation procedure, pain scores were applied to the entire procedure as a single treatment, as it is not typically possible to discern which individual lesion is contributing to a patient's pain. Chart reviews were also performed for evidence of complications. As this was a retrospective study, a post-ablation imaging protocol was not established and imaging ordering was primarily directed by the treating oncologist to monitor overall disease status. When available, the post-treatment imaging was evaluated by musculoskeletal radiologists and neuroradiologists for evidence of residual or recurrent tumor at the treated levels.

\section{Procedure Methods}

Pre-procedural planning was performed using cross-sectional imaging to determine pedicle access and the expected number of targeted ablations. Magnetic resonance imaging (MRI) was preferred due to better evaluation of the extent of vertebral body and pedicle involvement, as well as tumor extension into the central canal and/or neural foramen.

Prior to the procedure, written informed consent was obtained. Conscious sedation with fentanyl and midazolam was used in all cases, and no cases required 
general anesthesia. Local and periosteal anesthesia was achieved with a combination of $1 \%$ lidocaine and $0.25 \%$ bupivacaine. Fluoroscopy was used for imaging guidance for all of the RFA treatments, and computed tomography (CT) was used for the cryoablation treatment. The vertebral bodies were accessed via a transpedicular approach using a 10-gauge introducer working cannula. A bipedicular approach was used when the tumor involved more than $50 \%$ of the posterior wall.

RFA was performed by using the STAR Tumor Ablation System (DFINE, San Jose, Calif), consisting of the Spine STAR ablation instrument and the MetaSTAR generator. The number of performed ablations was determined by the tumor size and location on cross-sectional imaging in conjunction with real-time thermocouple temperature readings that correspond to the volume of each individual ablation zone. The ellipsoid ablation zone in relation to thermocouple temperatures is based on manufacturer thermal distribution curves with maximum dimensions of $30 \mathrm{~mm}$ long by $20 \mathrm{~mm}$ wide when the proximal thermocouple reaches $50^{\circ} \mathrm{C}$ and $20 \mathrm{~mm} \times$ $13 \mathrm{~mm}$ when the distal thermocouple is $50^{\circ} \mathrm{C}(16) . \mathrm{Op}$ timal tissue destruction occurs between $50-90^{\circ} \mathrm{C}(17)$. The mean cumulative ablation time per lesion was 9:45 minutes (range 2:30 - 24:13 minutes). To ensure ablation of most of the tumor at the treated level, multiple ablation zones were used with a mean of 8 overlapping ablation zones per treated level. The tumors ranged in size from $1.6 \mathrm{~cm}$ maximum diameter to involving the entire vertebral body with paraspinal extension. The mean temperature recorded at the proximal thermocouple on the electrode (representing the temperature reading at the most peripheral aspect of the ablation zone) was $50.9^{\circ} \mathrm{C}$, and the mean temperature recorded at the distal thermocouple was $74.9^{\circ} \mathrm{C}$.

Cryoablation was performed with Galil (Galil Medical, Yokneam, Israel) cryoprobes. Cryoablation was performed with a 10 minute freeze cycle followed by a 7 minute active thaw and then another 10 minute freeze cycle. CT images were obtained at both the 5 minute and 10 minute intervals. Neuroforaminal thermal monitoring was performed in the cryoablation case. Neural thermal protection involved neuroforaminal injection of CO2 (18-20). This was performed by placing an 18-gauge spinal needle in the region of the neuroforamen with placement of a thermocouple coaxially into the neuroforamen to measure temperatures. The thermal couple temperatures never went below $10^{\circ} \mathrm{C}(18-20)$.

After ablation, cement augmentation (StabiliT Vertebral Augmentation System; DFINE, San Jose, CA) was performed (35/36 lesions) via the same working cannula. The osteoblastic metastasis treated with cryoablation did not receive cement. Five (5/22) treatments were supplemented by central epidurals or selective nerve root blocks because of pre-existing radicular pain or pedicle involvement by tumor.

\section{Statistical Methods}

A paired unequal variance 2 -tailed Student $t$ test was used to compare pain scores before ablation with pain scores one week and one month after ablation; assuming a hypothetical mean difference of $2, P$-values $<0.05$ were considered statistically significant $(21,22)$. Treatment responses were categorized categorically with partial pain relief defined as $\geq 2$ point pain score reduction and complete relief defined as post-procedural pain score $\leq 1(7,23)$.

\section{Results}

Twenty-one patients with 36 spine metastases were treated with percutaneous ablation, either RFA or cryoablation, and RT to the same level between March 2012 and June 2014. One patient received 2 separate RFA treatments for a total of 21 RFA and one cryoablation procedures. This subgroup analysis includes 9 patients who were included in a previously reported cohort of 73 patients (119 lesions) that had vertebral RFA ablation (14). However, analysis of the effect of concurrent radiation was not evaluated in that prior study. There were 13 men (59\%) and 9 women (41\%). The mean patient age was 61.8 years (range, $30-84$ years). The most common types of primary tumor were non-small cell lung cancer $(38 \%, 8 / 21)$ and renal cell carcinoma $(24 \%, 5 / 21)$. Other tumors included breast cancer $(14 \%, 3 / 21)$, rectal cancer $(9 \%, 2 / 21)$, and single cases of bladder, angiosarcoma, and melanoma. Seven patients had tumors that are traditionally considered radiation resistant (renal cell, melanoma, or sarcoma). Of the vertebral bodies treated, $42 \%$ (15/36) were thoracic and $58 \%(21 / 36)$ were lumbar.

The radiation therapy treatments were variable depending on the institution and provider. The majority of patients received $30 \mathrm{~Gy}$ in 10 fractions (12/22). Other treatment regimens included stereotactic body radiation therapy (SBRT) (6/22), 20 Gy in 5 fractions $(1 / 22)$, and $8 \mathrm{~Gy}$ in a single fraction (1/22). Two treatment regimens were unknown.

Twenty-one RFA treatments and one cyroablation were performed in combination with RT. The pre-procedural mean worst pain score $(8.0, \mathrm{SD}=2.3$ ) 


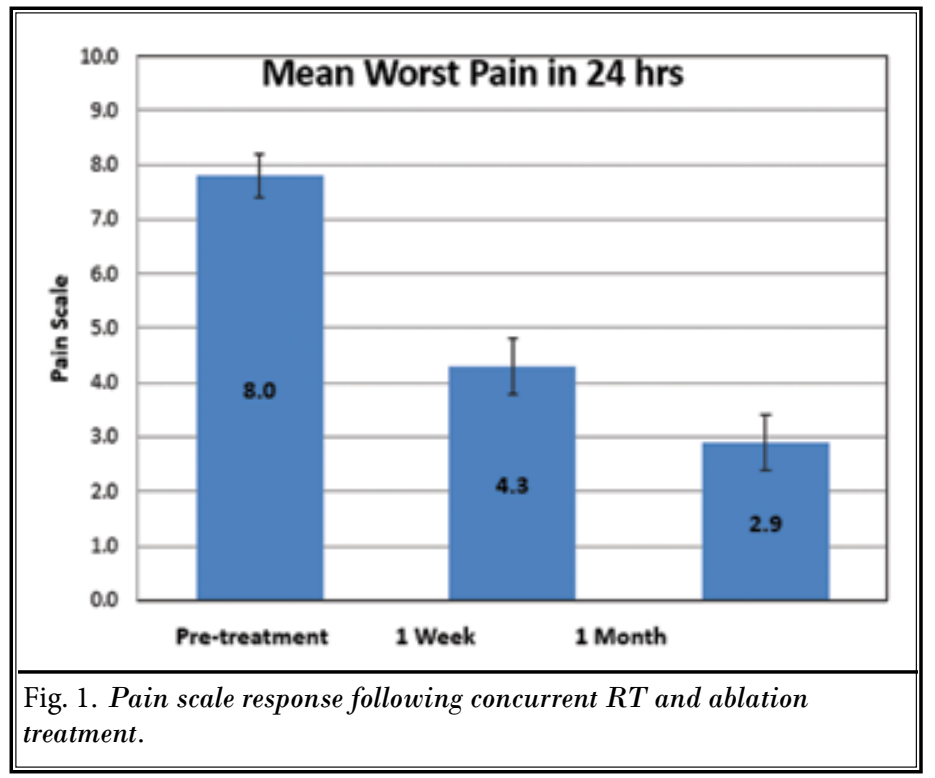

Table 1. Categorical response to treatment after concurrent $R T$ and ablation.

\begin{tabular}{|l|c|c|}
\hline \multicolumn{1}{|c|}{$\begin{array}{c}\text { Pain Score Change from } \\
\text { Baseline }\end{array}$} & \multicolumn{2}{c|}{ Time from RT and Ablation } \\
\cline { 2 - 3 } & 1 week & 1 month \\
\hline Complete & $5(24 \%)$ & $9(47 \%)$ \\
\hline At least partial $(\geq 2)$ & $16(76 \%)$ & $13(68 \%)$ \\
\hline Nonresponder $(<2)$ & $5(24 \%)$ & $6(32 \%)$ \\
\hline Total responses & 21 & 19 \\
\hline
\end{tabular}

\section{Change in Pain Medication at 1 month}

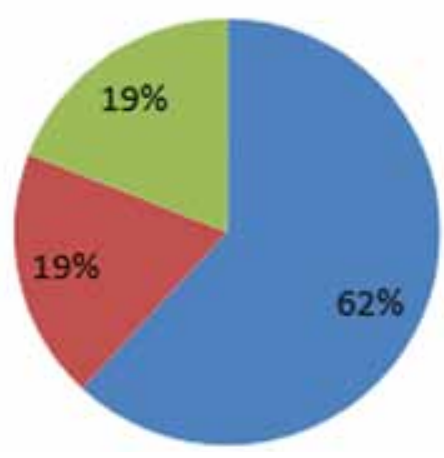

Less

More

Same significantly decreased at both one week (4.3, $\mathrm{SD}=3.1 ; P<.02)$ and 4 weeks $(2.9, \mathrm{SD}=3.3$; $P<.0003)$ following ablation treatments. The mean worst pain decreased by $3.8(95 \% \mathrm{Cl} 2.3$ - 5.4) at one week and $5.1(95 \% \mathrm{Cl} 3.3-6.9)$ at 4 weeks (Fig. 1). At least partial decrease ( $\geq$ 2 pain scale decrease) was reported after $76 \%$ $(16 / 21)$ and $68 \%(13 / 19)$ of treatments at one week and 4 weeks, respectively. Complete pain response (pain scale score $\leq 1$ ) was reported after $24 \%(5 / 21)$ and $47 \%(9 / 19)$ of treatments at one week and one month, respectively. No significant change in pain $(<2$ pain scale difference) was reported after $24 \%(4 / 21)$ and $32 \%$ $(6 / 19)$ of treatments at one week and 4 weeks, respectively (Table 1 ). One patient could not be reached during the one week follow-up period. At 4 weeks, one patient was deceased and 2 could not be reached.

Patient opioid use was decreased in $62 \%$ $(13 / 21)$, remained unchanged in $19 \%$ (4/21), and increased in $19 \%(4 / 21)$ at 4 week follow-up. General activity level at 4 weeks after ablation treatments was increased in $81 \%(17 / 21)$ and decreased in 19\% (4/21) (Fig. 2). One lesion (3\%; 1/36) was re-treated with RFA for recurrent pain and imaging evidence of recurrent tumor.

\section{Complications}

According to Society of Interventional Radiology guidelines, no major complication, such

\section{Change in Activity at 1} month

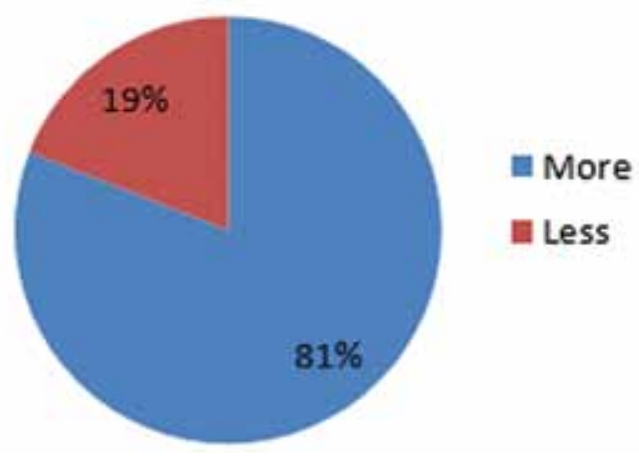

Fig. 2. Activity and pain medication use changes after concurrent RT and ablation. 
as permanent neural thermal injury, occurred as a result of spinal percutaneous ablation. There were post procedural infections. One patient with a tumor involving the pedicle had new radicular pain after RFA $(4.5 \%, 1 / 22)$ that resolved after transforaminal epidural.

\section{Post Treatment Imaging}

Thirteen (13/22) of the ablation treatments had follow-up imaging at least 3 months later, consisting of $\mathrm{CT}, \mathrm{MRI}$, and/or PET/CT (median 6 months; range $2-27$ months). Five patients had between 3 and 6 months, 6 patients had between $6-12$ months, and 2 patients had more than 12 months of post ablation imaging. Nine of the patients had limited or no follow-up imaging, therefore were not included in the post-procedure imaging evaluation. Six patients had $1-6$ weeks of follow-up imaging and 3 patients had no imaging follow-up.

Post-procedural imaging (median 6 months; range 2 - 27 months) showed stable treated disease in 12/13 patients at 3 months and 10/10 at 6 months, despite systemic progression of disease. Two cases (2/13) with epidural extension had retraction of tumor from the epidural space. There was imaging evidence of tumor progression at the ablation margins in one patient at 3 months. Another patient with less than 3 months of follow-up imaging had progressive vertebral collapse, increased retropulsion, and tumor progression at 4 weeks after concurrent therapy. The remaining lesions were stable during the duration of imaging follow-up available (Figs. 3-6).

\section{Discussion}

Percutaneous ablation, either RFA or cyroablation, and RT have different mechanisms of alleviating pain and causing tumor death in spinal metastases that may work synergistically by compensating for the other's shortcomings (15). Debilitating pain may be caused by spinal cord or nerve root compression from mass effect, pathologic fracture with mechanical instability, periosteal nociceptor stimulation from inflammation, tumor-derived products (e.g., tumor necrosis factor), or tumor-induced cytokines $(24,25)$. RFA uses thermal energy to destroy tissue surrounding an electrode, resulting in destruction of pain sensitive nerve fibers and decreased cytokine mediated pain from tumor necrosis $(25,26)$. Cryoablation relies on Joule-Thomson effect of rapid freezing with argon gas and thawing with helium gas as they expand to achieve cell death and ischemia from microvascular thrombosis (27). Both RFA and cryoablation are effective in treating osseous metastatic disease, but are dependent on the conduction of thermal energy which dissipates with distance from the probe tip, resulting in decreased efficacy around the tumor edge $(11-15,28)$. Conversely, RT is dependent on

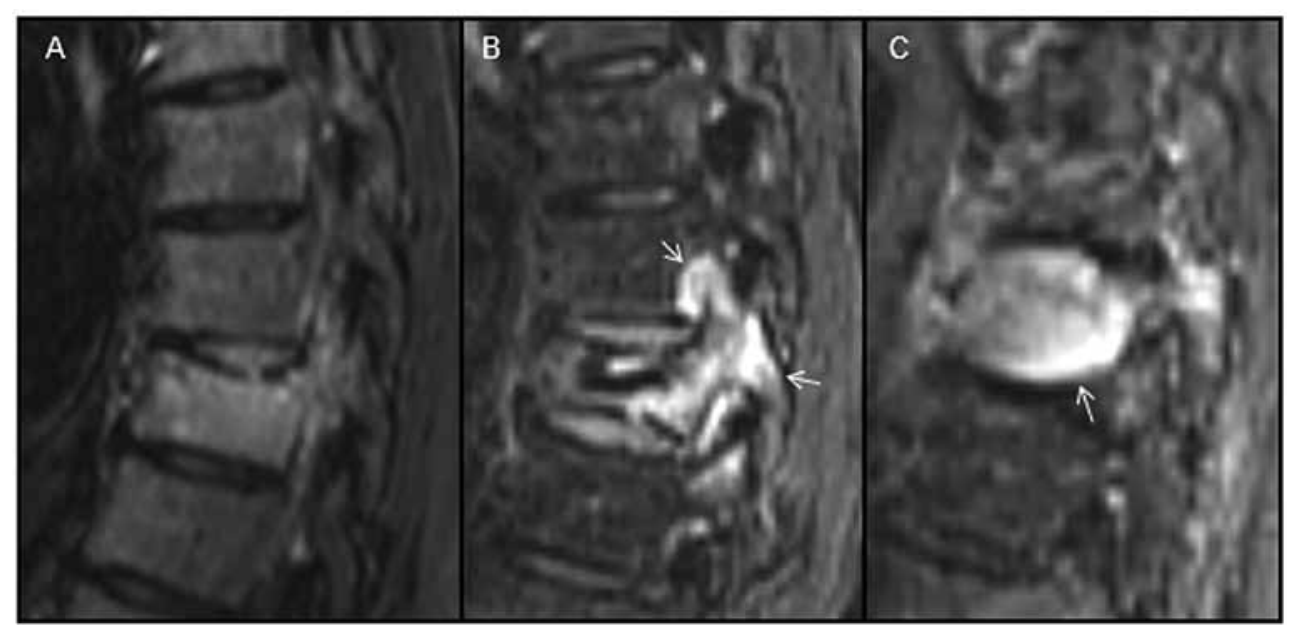

Fig. 3. A 62-year-old man with metastatic non-small cell lung carcinoma and painful pathologic compression fracture at T8. Sagittal TIFS post contrast image (A) one month prior to planned combined cEBRT and RFA show a pathologic fracture of T8 and diffuse enhancement of the vertebral body. Sagittal TIFS post contrast images (B, C) 1.5 months after treatment showing tumor progression at the peripheral margins of the ablation $(C)$ and within the posterior elements (B) (arrows). The patient's pre-procedural pain score (10/10) decreased to 3 at one week and 0 at 4 weeks. 

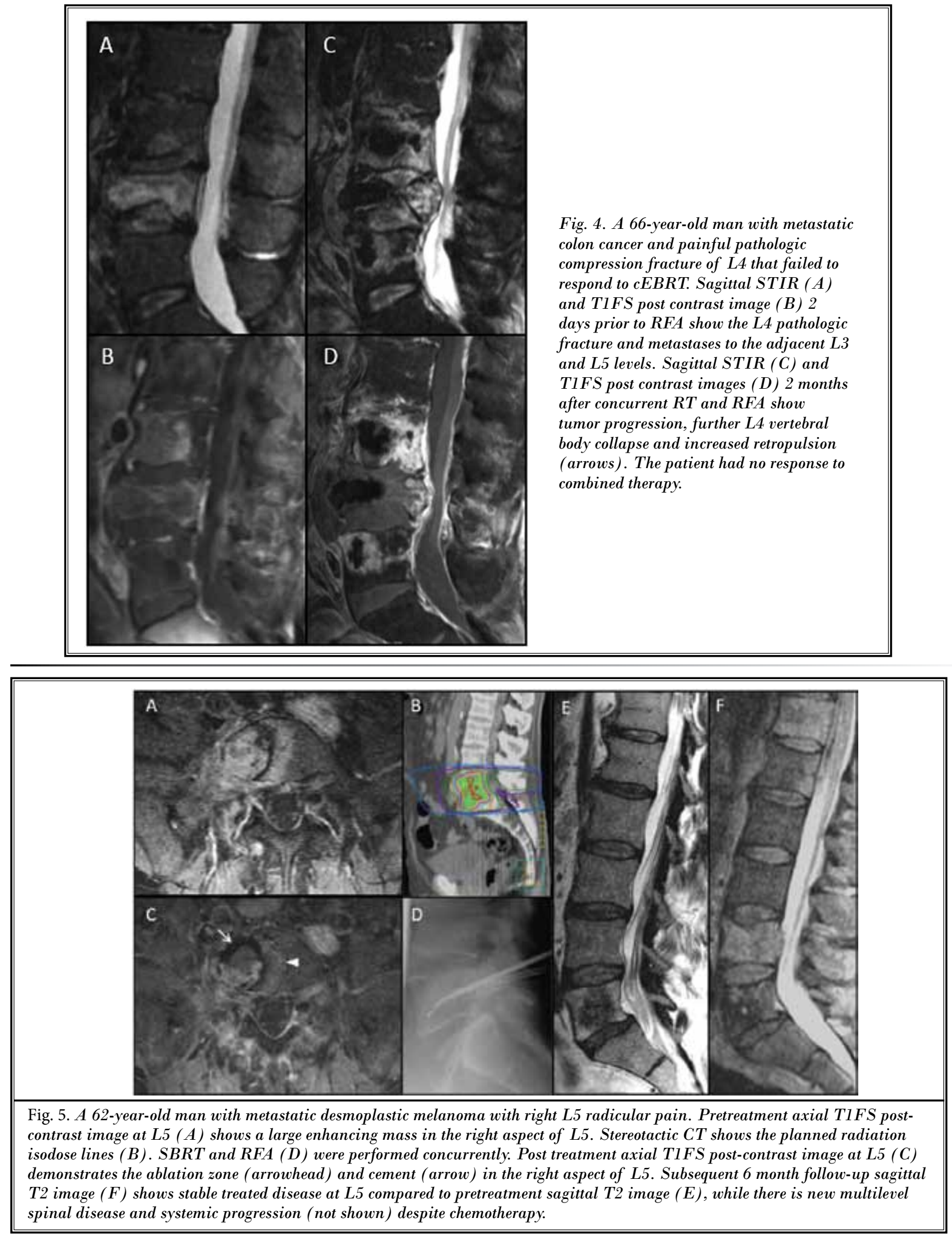
oxygen for cytotoxicity and is thought to be deficient in killing centrally located tumor cells that are often hypoxic (29). This theory was investigated in a retrospective cohort study by DiStaso et al (15), who compared the pain responses of 15 patients with solitary axial and appendicular osseous metastases treated with RFA followed by CEBRT ( 20 Gy in 5 fractions) with 30 patients treated with CEBRT alone. The combination therapy group included 5 (33\%; 5/15) vertebral and 2 (13\%; $2 / 15)$ sacral lesions, and the RT group included $2(6.6 \% ; 2 / 30)$ vertebral and $8(27 \% ; 8 / 30)$ sacral lesions. At 12 week follow-up, patients in the combined treatment group more frequently reported both complete [53\% (8/15) vs $17 \%(5 / 30) ; P=0.027$ ] and at least partial [93\% (14/15) vs 60\% (18/30); $P=0.048$ ] pain relief (15). However, only a small percentage of their treated lesions involved the spine and sacrum.

In this study, combined RFA and RT were effective at alleviating pain that was uncontrollable with conventional methods. The single case of combined RT and cryoablation had complete response. Cryoablation is typically used in osteoblastic metastases because the sclerotic bone lends to high impedance and prevents efficient radiofrequency tissue ablation. Some of the treated lesions were radiation resistant tumors based on histology or prior radiation failure, defined as persistent or recurrent symptoms, or imaging evidence of tumor progression after RT. The majority of patients were able to reduce opioid use and increase their activity, which may lead to an improved quality of life. In terms of safety, one patient $(4.5 \% ; 1 / 22)$ experienced temporary radicular pain attributable to RFA. However, there were no permanent neurological injuries. Given these encouraging results, a randomized control trial is warranted to compare the efficacy of combined RT and percutaneous ablation with RT alone.

In addition to pain relief, concurrent therapy controlled tumors locally in a majority of cases. Two patients with epidural extension of tumor had tumor retraction from the epidural space after treatment, which may have prevented or prolonged time to

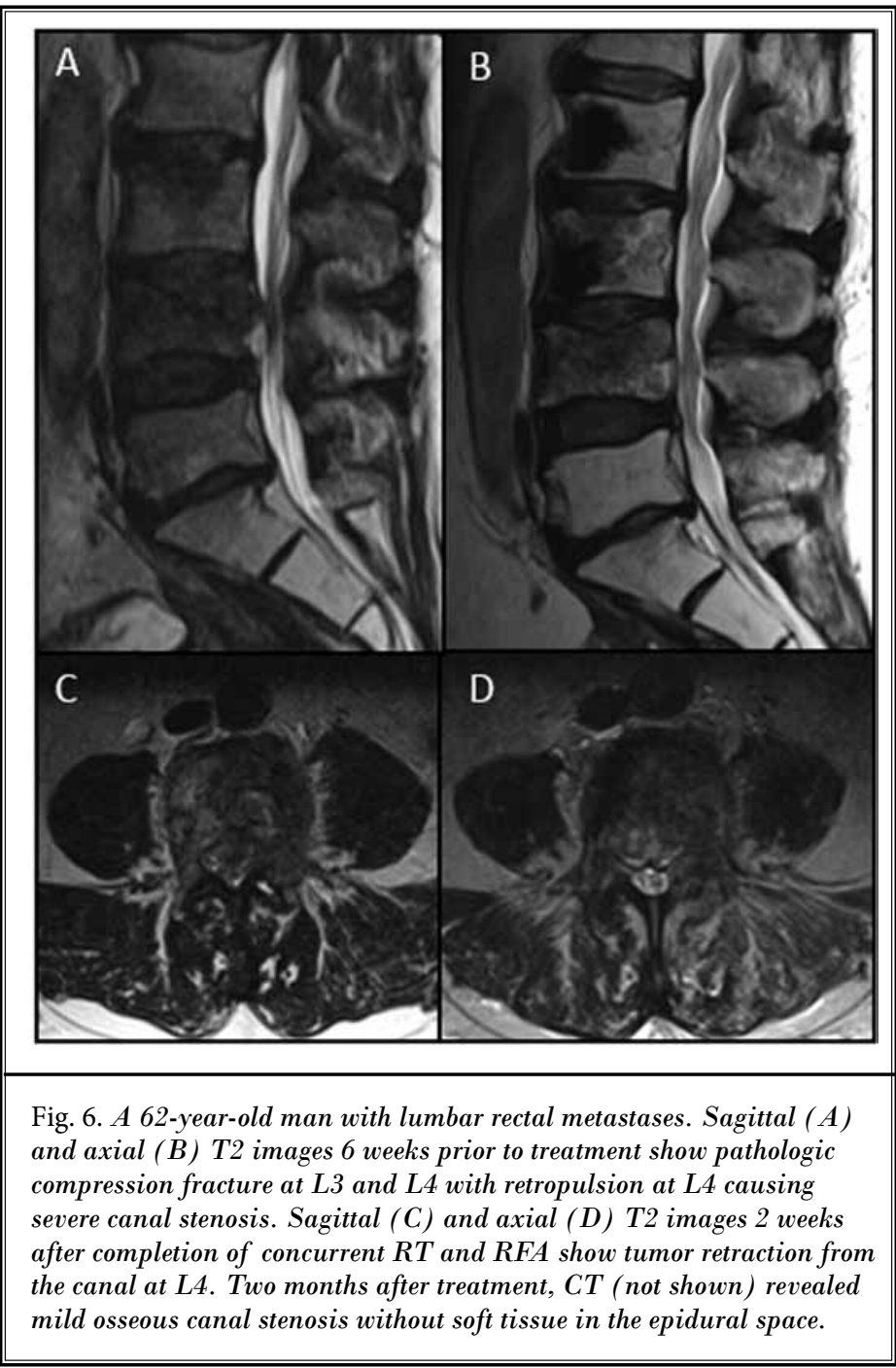

malignant spinal cord compression. These results are particularly intriguing given recent technical advances that permit ablation of metastases involving the posterior vertebral body and pedicles with navigational radiofrequency probes that permit real-time monitoring of the ablation volume $(14,16,30)$. Additionally, the risk of radiation myelopathy often precludes adequate treatment of tumor involving the posterior vertebral body, pedicles, neural foramina, and/or epidural space. Both ablation and SBRT of radiation resistant tumors alone have a higher likelihood of failure when the tumor involves the pedicles and neuroforamen $(14,31)$. Randomized control trials are needed to assess whether combined therapy achieves superior local tumor control compared with RT alone.

There are several limitations of this retrospective study. The efficacy of combined RFA and RT for pain palliation cannot be isolated from that of vertebral augmentation, which was per- 
formed after all RFA cases to stabilize or prevent pathologic fracture. Pain relief from cementoplasty alone in treatment of metastatic compression fractures has been shown to be effective over non-surgical management $(32,33)$. Cementoplasty is considered to produce pain relief via internal trabecular stabilization resulting in the reduced activity of periosteal nerves. The exothermic reaction resulting from polymethyl methacrylate production destroys adjacent pain fibers. Percutaneous ablation may have a synergistic pain relieving response with cementoplasty. Additionally, RFA has the theoretical advantage of preventing displacement of viable tumors into the venous plexus though venous plexus thrombosis and tumor cell death (34-37).

The prescribed RT regimens in this study were variable including both conventional single and fractionated RT, as well as SBRT, which may have different safety and efficacy profiles. There is ongoing debate regarding which RT regimen to employ (5). However, data are accumulating in support of SBRT for spinal metastases in oligometastatic disease and radioresistant histology. Future prospective, multi-armed trials should randomize patients with pathologic stable fractures to RT and vertebral augmentation; RT, ablation, and vertebral augmentation; and ablation plus augmentation in order to elucidate the most effective multimodality oftreatment in the palliative management of metastatic spine disease.

\section{Conclusion}

Combined radiation therapy and percutaneous ablation is safe and effective in palliating painful spinal metastases and controlling local tumor progression. This combined therapy is also effective in traditionally resistant tumor histology. Future prospective multiarmed studies should be designed to determine the palliative and local tumor control benefit of combined RT and percutaneous ablation, particularly for radiation resistant tumors and metastases involving the posterior vertebral body, pedicles, neural foramina, and/or epidural space that cannot be adequately treated with either modality alone.

\section{References}

1. Klimo P Jr, Schmidt MH. Surgical management of spinal metastases. Oncologist 2004; 9:188-196.

2. Janjan N, Lutz ST, Bedwinek JM, Hartsell WF, Ng A, Pieters RS Jr, Ratanatharathorn V, Silberstein EB, Taub RJ, Yasko AW, Rettenmaier A. Therapeutic guidelines for the treatment of bone metastasis: A report from the American College of Radiology Appropriateness Criteria Expert Panel on Radiation Oncology. J Palliat Med 2009; 12:417-426.

3. Dorrepaal KL, Aaronson NK, van Dam FS. Pain experience and pain management among hospitalized cancer patients. A clinical study. Cancer 1989; 63:593-598.

4. Togawa D, Lewandrowsky KU. The Pathophysiology of Spinal Metastases. Cancer in the Spine. Current Clinical Oncology. Humana Press, Totowa, NJ, 2006, pp 17-23.

5. Brown JE, Cook RJ, Major P, Lipton A, Saad F, Smith M, Lee KA, Zheng M, Hei YJ, Coleman RE. Bone turnover markers as predictors of skeletal complications in prostate cancer, lung cancer, and other solid tumors. J Natl Cancer Inst 2005; 97:59-69.

6. Witham TF, Khavkin YA, Gallia GL, Wo- linsky JP, Gokaslan ZL. Surgery insight: Current management of epidural spinal cord compression from metastatic spine disease. Nat Clin Pract Neurol 2006; 2:87-94.

7. Chow E, Harris K, Fan G, Tsao M, Sze WM. Palliative radiotherapy trials for bone metastases: A systematic review. J Clin Oncol 2007; 25:1423-1436.

8. Lutz S, Berk L, Chang E, Chow E, Hahn C, Hoskin P, Howell D, Konski A, Kachnic L, Lo S, Sahgal A, Silverman L, von Gunten C, Mendel E, Vassil A, Bruner DW, Hartsell W. Palliative radiotherapy for bone metastases: An ASTRO evidencebased guideline. Int J Radiat Oncol Biol Phys 2011; 79:965-976.

9. Lo SS, Sahgal A, Hartsell WF, Lutz ST, Kardamakis D, van der Linden Y, Hoskin PJ. The treatment of bone metastasis with highly conformal radiation therapy: A brave new world or a costly mistake? Clin Oncol (R Coll Radiol) 2009; 21:662-664.

10. Valesin Filho ES, de Abreu LC, Lima GH, de Cubero DI, Ueno FH, Figueiredo GS, Valenti VE, Monteiro CB, Wajnsztejn R, Fujiki EN, Neto MR, Rodrigues LM. Pain and quality of life in patients undergoing radiotherapy for spinal metastatic dis- ease treatment. Int Arch Med 2013; 6:6.

11. Kurup AN, Callstrom MR. Ablation of musculoskeletal metastases: Pain palliation, fracture risk reduction, and oligometastatic disease. Tech Vasc Interv Radiol 2013; 16:253-261.

12. Callstrom MR, Charboneau JW, Goetz MP, Rubin J, Wong GY, Sloan JA, Novotny PJ, Lewis BD, Welch TJ, Farrell MA, Maus TP, Lee RA, Reading CC, Petersen IA, Pickett DD. Painful metastases involving bone: Feasibility of percutaneous CT- and US-guided radio-frequency ablation. Radiology 2002; 224:87-97.

13. Dupuy DE, Liu D, Hartfeil D, Hanna L, Blume JD, Ahrar K, Lopez R, Safran $H$, DiPetrillo T. Percutaneous radiofrequency ablation of painful osseous metastases: A multicenter American College of Radiology Imaging Network trial. Cancer 2010; 116:989-997.

14. Anchala PR, Irving WD, Hillen TJ, Friedman MV, Georgy BA, Coldwell DM, Tran ND, Vrionis FD, Brook A, Jennings JW. Treatment of metastatic spinal lesions with a navigational bipolar radiofrequency ablation device: A multicenter retrospective study. Pain Physician 2014; 17:317-327.

15. Di Staso M, Zugaro L, Gravina GL, Bon- 
fili P, Marampon F, Di Nicola L, Conchiglia A, Ventura L, Franzese P, Gallucci M Masciocchi C, Tombolini V. A feasibility study of percutaneous radiofrequency ablation followed by radiotherapy in the management of painful osteolytic bone metastases. Eur Radiol 2011; 21:2004-2010.

16. Hillen TJ, Anchala P, Friedman MV, Jennings JW. Treatment of metastatic posterior vertebral body osseous tumors by using a targeted bipolar radiofrequency ablation device: Technical note. Radiology 2014; 273:261-267.

17. Brace CL. Radiofrequency and microwave ablation of the liver, lung, kidney, and bone: What are the differences? Curr Probl Diagn Radiol 2009; 38:135-143.

18. Buy X, Tok CH, Szwarc D, Bierry G, Gangi A. Thermal protection during percutaneous thermal ablation procedures: Interest of carbon dioxide dissection and temperature monitoring. Cardiovasc Intervent Radiol 2009; 32:529-534.

19. Klass D, Marshall T, Toms A. CT-guided radiofrequency ablation of spinal osteoid osteomas with concomitant perineural and epidural irrigation for neuroprotection. Eur Radiozo09; 19:2238-2243.

20. Rybak LD, Gangi A, Buy X, La Rocca Vieira R, Wittig J. Thermal ablation of spinal osteoid osteomas close to neural elements: Technical considerations. AJR Am J Roentgenol 2010; 195:W/293-W298.

21. Goetz MP, Callstrom MR, Charboneau JW, Farrell MA, Maus TP, Welch TJ, Wong GY, Sloan JA, Novotny PJ, Petersen IA, Beres RA, Regge D, Capanna R, Saker MB, Grönemeyer DH, Gevargez A, Ahrar K, Choti MA, de Baere TJ, Rubin J. Percutaneous image-guided radiofrequency ablation of painful metastases involving bone: A multicenter study. J Clin Oncol 2004; 22:300-306.

22. Wang XS, Rhines LD, Shiu AS, Yang JN,
Selek U, Gning I, Liu P, Allen PK, Azeem SS, Brown PD, Sharp HJ, Weksberg DC, Cleeland CS, Chang EL. Stereotactic body radiation therapy for management of spinal metastases in patients without spinal cord compression: A phase 1-2 trial. Lancet Oncol 2012; 13:395-402.

23. Dexter F, Chestnut DH. Analysis of statistical tests to compare visual analog scale measurements among groups. Anesthesiology 1995; 82:896-902.

24. Mundy GR. Metastasis to bone: Causes, consequences and therapeutic opportunities. Nat Rev Cancer 2002; 2:584-593.

25. Mannion RJ, Woolf CJ. Pain mechanisms and management: A central perspective. Clin J Pain 2000; 16:S144-S156.

26. Cleeland CS, Gonin R, Hatfield AK, Edmonson JH, Blum RH, Stewart JA, Pandya KJ. Pain and its treatment in outpatients with metastatic cancer. $N$ Engl J Med 1994; 330:592-596.

27. Theodorescu D. Cancer cryotherapy: Evolution and biology. Rev Urol 2004; 6:S9-Sig.

28. Callstrom MR, Dupuy DE, Solomon SB, Beres RA, Littrup PJ, Davis KW, PazFumagalli R, Hoffman C, Atwell TD, Charboneau JW, Schmit GD, Goetz MP, Rubin J, Brown KJ, Novotny PJ, Sloan JA. Percutaneous image-guided cryoablation of painful metastases involving bone: Multicenter trial. Cancer 2013; 119:1033-1041.

29. Hellevik T, Martinez-Zubiaurre I. Radiotherapy and the tumor stroma: The importance of dose and fractionation. Front Oncol 2014; 4:1.

30. Buy X, Basile A, Bierry G, Cupelli J, Gangi $A$. Saline-infused bipolar radiofrequency ablation of high-risk spinal and paraspinal neoplasms. AJR Am J Roentgenol 2006; 186:S322-S326.

31. Balagamwala EH, Angelov L, Koyf- man SA, Suh JH, Reddy CA, Djemil T. Single-fraction stereotactic body radiotherapy for spinal metastases from renal cell carcinoma. J Neurosurg Spine 2012; 17:556-564.

32. Chew C, Craig L, Edwards R, Moss J, O'Dwyer PJ. Safety and efficacy of percutaneous vertebroplasty in malignancy: A systematic review. Clin Radiol 2011; 66:63-72.

33. Berenson J, Pflugmacher R, Jarzem $P$, Zonder J, Schechtman K, Tillman JB, Bastian L, Ashraf T, Vrionis F. Balloon kyphoplasty versus non-surgical fracture management for treatment of painful vertebral body compression fractures in patients with cancer: A multicentre, randomised controlled trial. Lancet Oncol 2011; 12:225-235.

34. Georgy BA, Wong W. Plasma-mediated radiofrequency ablation assisted percutaneous cement injection for treating advanced malignant vertebral compression fractures. AJNR Am J Neuroradiol 2007; 28:700-705.

35. Munk PL, Rashid F, Heran MK, Papirny M, Liu DM, Malfair D, Badii M, Clarkson PW. Combined cementoplasty and radiofrequency ablation in the treatment of painful neoplastic lesions of bone. J Vasc Interv Radiol 2009; 20:903-911.

36. Schaefer O, Lohrmann C, Herling M, Uhrmeister P, Langer M. Combined radiofrequency thermal ablation and percutaneous cementoplasty treatment of a pathologic fracture. J Vasc Interv Radiol 2002; 13:1047-1050.

37. Toyota N, Naito A, Kakizawa H, Hieda M, Hirai N, Tachikake T, Kimura T, Fukuda $\mathrm{H}$, Ito K. Radiofrequency ablation therapy combined with cementoplasty for painful bone metastases: Initial experience. Cardiovasc Intervent Radiol 2005; 28:578-583. 
